\title{
Shortened first-line TB treatment in Brazil: potential cost savings for patients and health services
}

\author{
Anete Trajman ${ }^{1,2,3^{*}}$, Mayara Lisboa Bastos ${ }^{1,3}$, Marcia Belo ${ }^{3,4}$, Janaína Calaça ${ }^{3}$, Júlia Gaspar ${ }^{3}$, \\ Alexandre Martins dos Santos ${ }^{3}$, Camila Martins dos Santos ${ }^{3}$, Raquel Trindade Brito ${ }^{5}$, William A. Wells ${ }^{6,7}$, \\ Frank G. Cobelens ${ }^{8}$, Anna Vassall ${ }^{9}$ and Gabriela B. Gomez ${ }^{8,9}$
}

\begin{abstract}
Background: Shortened treatment regimens for tuberculosis are under development to improve treatment outcomes and reduce costs. We estimated potential savings from a societal perspective in Brazil following the introduction of a hypothetical four-month regimen for tuberculosis treatment.

Methods: Data were gathered in ten randomly selected health facilities in Rio de Janeiro. Health service costs were estimated using an ingredient approach. Patient costs were estimated from a questionnaire administered to 126 patients. Costs per visits and per case treated were analysed according to the type of therapy: self-administered treatment (SAT), community- and facility-directly observed treatment (community-DOT, facility-DOT).

Results: During the last 2 months of treatment, the largest savings could be expected for community-DOT; on average USD 17,351-18,203 and USD 43,660-45,856 (bottom-up and top-down estimates) per clinic. Savings to patients could also be expected as the median (interquartile range) patient-related costs during the two last months were USD 108 (13-291), USD 93 (36-239) and USD 11 (7-126), respectively for SAT, facility-DOT and community-DOT.

Conclusion: Introducing a four-month regimen may result in significant cost savings for both the health service and patients, especially the poorest. In particular, a community-DOT strategy, including treatment at home, could maximise health services savings while limiting patient costs. Our cost estimates are likely to be conservative because a 4-month regimen could hypothetically increase the proportion of patients cured by reducing the number of patients defaulting and we did not include the possible cost benefits from the subsequent prevention of costs due to downstream transmission averted and rapid clinical improvement with less side effects in the last two months.
\end{abstract}

Keywords: Tuberculosis, Antitubercular agents, Brazil, Directly observed therapy, Health care costs

\section{Background}

Globally, in 2013, there were nine million new cases and 1.5 million deaths from tuberculosis (TB), with $95 \%$ of the deaths occurring in low- and middle-income countries [1]. Major advances in diagnostic technologies [2-6] and an increase in treatment coverage [1] have largely contributed to improvements in TB control worldwide. However,

\footnotetext{
*Correspondence: atrajman@gmail.com

${ }^{1}$ Federal University of Rio de Janeiro, Rio de Janeiro, Brazil

${ }^{2}$ McGill University, Montreal, Canada

Full list of author information is available at the end of the article
}

the length of the current first-line standard regimen (total of six months, including a 2-month intensive phase with four drugs and a 4-month continuation phase with two drugs), as well as the side effects of this treatment, continue to hamper treatment adherence and acceptability. In addition, treatment costs represent a substantial expenditure for National TB Programmes (NTP) [1, 7], while the costs borne by patients can be disproportionally high considering the poorest subgroups of the population affected by the disease $[8,9]$. Thus, substantial investments and international efforts are being put into the development of 
shortened new regimens, mainly aiming to reduce the length of the continuation phase [10-13].

Brazil has been an early adopter of new technologies in general and of new TB technologies in particular $[14,15]$. Accurate information on costs is an important input for planning and budgeting by the Brazilian NTP when considering funding the introduction of new technologies. Introducing a 4-month regimen for $\mathrm{TB}$ in a high service cost scenario, such as Brazil, may lead to overall savings from the health service perceptive [16]. However, initial published estimates have been based on global estimates of treatment costs from the World Health Organisation (WHO), rather than locally-collected data and have excluded costs from a patient perspective [16]. Yet, the importance of including patient cost into policy decisions is reflected in and will help track progress of WHO's post2035 targets, which include a statement that no household should suffer from catastrophic expenditures related to TB [17]. Previous studies suggest that cost savings from the patient side may be an important advantage of shortened TB regimens. Patient costs during the last two months of first-line treatment were recently shown to correspond to 89 and $77 \%$ of the 2-month average national incomes in Tanzania and Bangladesh [18]. However, to date, there is scarce information about actual resource utilisation, treatment models in place, and how costs related to TB treatment (for patients or the health service) vary depending on the treatment model used. Thus, the purpose of this study is to assess health service and patient costs during the last two months of the current first-line regimen and to explore potential savings following the introduction of a 4-month regimen in Rio de Janeiro, Brazil.

\section{Methods}

\section{Study setting}

The city of Rio de Janeiro has one of the highest TB incidence rates in Brazil [19], with 90 new cases per 100,000 population reported yearly [19]. This high incidence has been linked to structural determinants such as urban violence, poverty, social inequity, and a complex healthcare system [20]. Although, nationally, all TB treatment is available through public facilities free-ofcharge and supervised treatment is mandatory, there is important variation among clinics of the treatment models offered. Currently, there are three types of primary care facilities in Rio [21]: (i) family health clinics, where family health teams composed of one physician, one nurse, one aid nurse, and six community healthcare workers provide home visits and clinic-based consultations. Each team is responsible for 1,000 to 1,500 families living in their catchment area; (ii) classic health facilities, where only scheduled appointments with general physicians, specialists, and nurses are available; and (iii) mixed clinics providing both types of services. All facilities provide self-administered therapy (SAT) for TB treatment. However, not all clinics have implemented directly observed therapy (DOT); in those where it has been implemented, two treatment models are available: facility-based and community-based DOT (facility-DOT and community-DOT). Facility-DOT patients have to present to the clinics for pill collection and intake; while community-DOT patients receive daily visits from health care agents distributing pills and supervising intake on working days. The frequency of supervision may also vary across facilities - at least three times weekly, ideally five times, during the first 2 months; twice weekly, ideally five times, for the remaining 4 months of treatment [22] All patients have monthly visits with a physician for clinical, bacteriological and (eventually) radiological evaluation, regardless of the treatment model.

\section{Data collection and analysis}

To ensure a representative range of costs estimates from different settings, we purposively selected four geographical areas to obtain a balance between the municipality of Rio and peri-urban areas. We then randomly sampled 12 facilities from a census of all eligible facilities currently treating at least $50 \mathrm{~TB}$ patients (excluding hospitals), stratified by workload (ratio of TB patients per healthcare workers) and type of clinic (family health clinics, classic health facilities, and mixed clinics).

\section{Health service costs}

Costs from a healthcare provider's perspective were estimated using an ingredient approach [23-25] for each participating facility. We included capital costs (building, equipment, furniture) and recurrent costs (labour, supplies, utilities, drugs, and monitoring and evaluation). We interviewed personnel, observed consultations and reviewed financial and activity reports to estimate the resource use for each input. In cases where resources were shared between TB and other services, we used the following allocation methods: costs for building space were estimated by multiplying the total building space by the average rental price per square meter, sourced from local rental offices. Building space was then allocated according to service distribution within the clinic's rooms and time used (from staff interviews and observations). For equipment and furniture, we sourced local market prices for all items and allocated to TB proportionally to the time used and number of patients (from staff interviews and clinic records); staff time dedicated to TB was allocated following observations of practices and staff interviews.

We used a combination of bottom-up and top-down approaches to calculate unit costs. In a bottom-up approach, we identified the resources used within a certain input type and after allocating a value to them, we added 
them to calculate unit costs; for the top-down approach, we divided the total expenditure for a given input type by the units of activity. We adopted a micro-costing approach that mixed both methods. Drug costs are only reported as bottom-up estimates because records for drug expenditures were not reliable at facility-level. In Brazil, drug expenditure is centralized; and therefore not accessible at the facility level. We verified the prices of drugs and consumables sourced from suppliers with international databases [26]. Capital costs were annualized and discounted at $3 \%$ per year. All prices were collected in local currency.

We calculated cost per visit and episode costs (cost per person treated) by treatment modality and site. We extracted information on the total number of nonmultidrug resistant $\mathrm{TB}$ patients being treated for each treatment modality (SAT, facility- and community-DOT) from service statistics for the period covered. We estimated the episode costs by month by multiplying the number of visits in this period by the unit costs. To allocate costs to the last two months of treatment, we first estimated the number of visits using two methods: (i) assuming a $10 \%$ default rate after the 4th month, we estimated that the number of monthly visits would be $45 \%$ of the number of visits if guidelines were fully adhered to; (ii) we estimated the number of visits during the last two months as reported by patients in the questionnaires. We did not include programme costs, defined as the costs associated with general support to service delivery (i.e., not directly linked to individual patients; for example administration, management, and supervision activities).

Finally, we estimated the total potential annual savings due to the introduction of a shortened first-line TB regimen considering that 76,020 persons were treated with TB in 2013 [1] and assuming a distribution of treatment models as seen in our participating clinics.

\section{Patient costs}

All TB patients attending (or having home visits by a community health worker) at a participating clinic on their 5th or 6th month of treatment were invited to participate. After obtaining informed consent, data on demographics, assets, type of TB treatment and both direct and indirect costs were gathered. The questionnaire used to collect patient-related costs was based on a validated tool for patient costs developed by USAID and available online [27]. Direct costs included all out-ofpocket expenditure, while indirect costs included productivity loss/opportunity cost to the household, coping costs (selling of assets and borrowed money) and carer's costs. With regards to productivity loss/opportunity costs to the household, we considered both transport time seeking care and additional days off-work due to the disease. The value of an hour was estimated using four different methods: (i) 2013 minimum wage; (ii) midpoint of the estimated family monthly income using Critério Brasil [28] divided by the number of persons living in the house; (iii) the shadow salary [29], estimated using the union's hourly salary, according to the profession declared (for those without employment, we valued their hourly cost based on the minimal wage); and (iv) the declared income. We assumed a 44-hour weekly contract for participants employed [30].

Costs per visit were multiplied by the number of visits in the last 2 months to arrive at total costs. We calculated the ratio of total costs during the last 2 months of treatment to the estimated monthly income by estimation method. We considered total costs during the last 2 months to be catastrophic when they represented over $40 \%$ of the monthly income [31].

Data collection took place from June 2013 to May 2014. The average exchange rate used was USD $1=B R L$ 2.16. All health service cost analyses were performed using EXCEL 2013 (Microsoft, USA). Statistics analyses were performed in SPSS 21 (IBM, USA). Mean costs and standard deviations (SD) were compared using independent $t$-test.

\section{Ethical approval}

The study was approved by the Institutional Review Board at the Universidade Gama Filho (268.778) in Rio de Janeiro; the Comitê de Ética em Pesquisa, Prefeitura do Rio de Janeiro (164A/2013); and the Observational and Interventions Research Ethics Committee of the London School of Hygiene and Tropical Medicine, UK (6322).

\section{Results}

The 12 randomly selected clinics provided services to neighbourhoods with a wide range of income (average monthly income USD 209-USD 2,538) and TB burden (incidence rate 51.2-382.4 new TB cases per 100,000 population per year). All facilities offered SAT and at least one type of DOT ( 9 offered facility- DOT while the other three offered community-DOT). The facilities presented a wide workload range (50-383 staff registered; 66-332 patients per year). Of 12 clinics approached, ten $(83.3 \%)$ agreed to participate (Table 1$)$.

\section{Health service costs}

Service utilisation for $\mathrm{TB}$ is presented by facility in Additional file 1: Table $\mathrm{S} 1$ in the supplementary material. A total of $1,140 \mathrm{~TB}$ patients were treated during 2013. Of these, seven were multidrug-resistant TB patients $(0.6 \%)$ treated in one facility only. These patients were not included in the analysis. Of the 1,133 new or previously treated TB patients, 739 
Table 1 Characteristics of all randomly selected clinics

\begin{tabular}{|c|c|c|c|c|c|c|c|c|}
\hline \multicolumn{2}{|c|}{$\begin{array}{l}\text { Study } \\
\text { Information }\end{array}$} & \multicolumn{4}{|c|}{ Clinic information } & \multicolumn{3}{|c|}{ Neighbourhood information } \\
\hline Clinic & Included & $\begin{array}{l}\mathrm{n} \text { FTE } \\
\text { staff }\end{array}$ & $\begin{array}{l}\text { n TB } \\
\text { patients/ } \\
\text { year }\end{array}$ & Type [43] & TB treatment model & $\begin{array}{l}\text { Population } \\
(2010) \text { [44] }\end{array}$ & $\begin{array}{l}\text { TB incidence } \\
\text { rate }^{a}[45]\end{array}$ & $\begin{array}{l}\text { Average monthly income } \\
\text { (2013USD) [44] }\end{array}$ \\
\hline 1 & No & $137[43]$ & 76 [43] & Family health clinic & SAT and community-DOT & 10,086 & 152.2 & $2,538.1$ \\
\hline 2 & Yes & 56 & 51 & Family health clinic & SAT and community-DOT & 7,390 & 51.2 & 610.3 \\
\hline 3 & Yes & 147 & 163 & Family health clinic & SAT and community-DOT & 58,007 & 382.4 & 208.8 \\
\hline 4 & Yes & 89 & 117 & Mixed clinic & SAT and facility-DOT & 23,861 & 220.0 & 401.5 \\
\hline 5 & Yes & 138.5 & 66 & Mixed clinic & SAT and facility-DOT & 133,315 & 108.1 & 356.0 \\
\hline 6 & Yes & 173.5 & 98 & Classic health facility & SAT and facility-DOT & 286,527 & 79.7 & 387.8 \\
\hline 7 & Yes & 268 & 26 & Classic health facility & SAT and facility-DOT & 182,722 & 109.4 & 249.2 \\
\hline 8 & Yes & 111 & 132 & Mixed clinic & SAT and facility-DOT & 137,710 & 103.0 & $1,253.6$ \\
\hline 9 & Yes & 188 & 195 & Mixed clinic & SAT and facility-DOT & 41,524 & 112.8 & 357.5 \\
\hline 10 & Yes & 76.5 & 107 & Mixed clinic & SAT and facility-DOT & 14,794 & 95.6 & $1,835.7$ \\
\hline 11 & Yes & 256 & 178 & Classic health facility & SAT and facility-DOT & 211,068 & 167.2 & 315.6 \\
\hline 12 & No & $201[43]$ & $254[43]$ & Mixed clinic & SAT and facility-DOT & 33,180 & 56.8 & 480.8 \\
\hline
\end{tabular}

per 100,000 inhabitants, in 2009; $n$ number; FTE full-time equivalent; SAT self-administered therapy; DOT directly observed therapy

(65 \%) were DOT patients (530, $47 \%$ in facility-DOT and 209, $18 \%$ in community-DOT). The total number of visits was estimated to be 55,876, of which $37 \%(n=20,691)$ were community visits. Only $4 \%$ of all visits $(n=2,325)$ were SAT visits.

The unit and total costs by treatment type as well as drug and episode costs by treatment phase and type are presented in Additional file 1: Table S2 in supplementary material. Detailed unit costs by cost input are displayed in Additional file 1: Table S3, also in supplementary material. Briefly, the highest mean unit cost excluding drugs was estimated for SAT at USD 31.1 (range 8.0-93.1) and USD 61.1 (range 18.3-264.4); the estimates for facilityDOT were USD 8.2 (range 3.9-19.7) and USD 14.8 (range 5.3-21.7); while for community-DOT, these were USD 5.4 (range 5.2-5.7) and USD 14.5 (range 13.0-16.0), bottom-up and top-down respectively. The highest mean cost per patient completing treatment was observed for community-DOT (USD 571.1 and USD 1,477, bottom-up and top-down respectively) but varied greatly among sites (ranges 549.2-594.1 and 1,331-1,623). Mean total annual costs per facility were estimated at USD 43,439 and 81,465 , bottom-up and top-down respectively. Staff and building costs represented the main type of costs in both SAT and facility- DOT, whereas for community- DOT, the main driver of costs was staff and overhead costs (Additional file 1: Table S3).

Table 2 presents the mean potential cost savings in the last two months of treatment by utilisation assumption (see Additional file 1: Table S4 for top-down estimates and Additional file 1: Table S5 for bottom-up estimates by site). Our estimated savings varied by clinic and type of treatment. The largest savings could be expected for community-DOT, reaching for example, up to USD 67,226 (Additional file 1: Table S4) at a single clinic. We estimated that the national introduction of a shortened regimen could potentially save up to USD 8,345,775 and 16,166,046 (top-down and bottom-up estimates) savings in treatment costs related to the two last months of treatment.

\section{Patient costs}

We interviewed a total of 126 patients in the ten participating clinics. The median age among our sample was 43.0 (interquartile range $27.8-55.4)$ years, $61 \%(n=77)$ were male, $78 \%(n=93)$ belonged to the three lowest socioeconomic classes. Participants' characteristics are detailed in Additional file 1: Table S6 in supplementary material.

The estimated value of a productive hour using the different methods was: (i) minimum wage, USD $1.4 / \mathrm{h}$; (ii) family monthly income per capita, USD 1.0 (IQR 0.7-1.8)/h; (iii) shadow price, USD 2.1 (IQR 2.0-2.2)/h; and (iv) declared income, USD 1.9 (IQR 1.5-3.2)/h. Among patients declaring their income $(n=49)$, the median declared monthly income was USD 370 (IQR 298-625). Using the shadow salary method, the median monthly income was USD 420 (IQR 405-435); while using the family income per capita, the median monthly income was estimated at USD 195 (IQR 133-359).

Table 3 shows direct costs as well as indirect by method to value a productive hour. Mean direct costs during the last 2 months were USD 96 for the whole sample. The mean total indirect costs varied depending 
Table 2 Potential savings: episode and total costs by type of treatment in the last two months for different utilisation assumptions, USD 2013

\begin{tabular}{|c|c|c|}
\hline & Top-down; mean (range) & Bottom-up; mean (range) \\
\hline \multicolumn{3}{|l|}{ EPISODE COSTS } \\
\hline \multicolumn{3}{|l|}{ Facility-DOT } \\
\hline $45 \%$ continuation phase & $283.7(108.5-410.5)$ & $160.6(82.7-373.3)$ \\
\hline Patient utilisation & $286.9(109.6-415.2)$ & $162.3(83.5-377.6)$ \\
\hline \multicolumn{3}{|l|}{ SAT } \\
\hline $45 \%$ continuation phase & $115.1(38.9-470.8)$ & $61.6(20.8-168.5)$ \\
\hline Patient utilisation & $127.7(42.6-525.0)$ & $68.0(22.4-187.6)$ \\
\hline \multicolumn{3}{|l|}{ Community-DOT } \\
\hline $45 \%$ continuation phase & $441.5(397.6-485.6)$ & $169.8(162.8-176.8)$ \\
\hline Patient utilisation & $463.8(417.6-510.1)$ & $178.1(170.8-185.6)$ \\
\hline \multicolumn{3}{|c|}{ Average total costs by treatment type } \\
\hline \multicolumn{3}{|l|}{ Facility-DOT } \\
\hline $45 \%$ continuation phase & $16,834(2,824-24,631)$ & $10,083(848-18,260)$ \\
\hline Patient utilisation & $17,024(2,855-24,911)$ & $10,194(857-18,467)$ \\
\hline \multicolumn{3}{|l|}{ SAT } \\
\hline $45 \%$ continuation phase & $2,021(65.6-4,701)$ & $1,287(55.4-3,562)$ \\
\hline Patient utilisation & $2,227(72.5-5,157)$ & $1,407(61.1-3,884)$ \\
\hline \multicolumn{3}{|l|}{ Community-DOT } \\
\hline $45 \%$ continuation phase & $43,660(23,308-64,012)$ & $17,351(8,486-26,216)$ \\
\hline Patient utilisation & $45,856(24,486-67,226)$ & $18,203(8,907-27,500)$ \\
\hline \multicolumn{3}{|l|}{ Average total costs per facility } \\
\hline $45 \%$ continuation phase & $24,221(4,010-64,954)$ & $12,824(1,316-26,551)$ \\
\hline Patient utilisation & $25,018(4,159-68,276)$ & $13,204(1358-27873)$ \\
\hline
\end{tabular}

DOT directly observed therapy; SAT self-administered therapy

Utilisation assumptions: 1) $45 \%$ continuation phase. In this scenario we calculated the costs in the last two months of treatment as a proportion of the continuation phase costs; 2) Patient utilisation. In this alternative scenario, costs in the last two months of treatment are calculated using the reported number of visits by patients interviewed

on the method used to value a productive hour: using the minimum wage and the SES income per capita, the mean total indirect costs was USD 316; using the income per activity, this was USD 332 for the whole sample. If we restrict the sample to those reporting an income, then the mean total indirect costs is estimated at USD 357.

When comparing the mean total costs by participant's characteristics, these were higher for patients belonging to lower socioeconomic classes (mainly due to higher indirect costs), and patients under SAT and facility-DOT regimens (Table 4). However, while the difference was statistically significant when comparing socioeconomic classes, it was not statistically significant when comparing type of treatment. Total costs during the last two months of treatment corresponded to a maximum of $26.3 \%(1.6-41.8 \%)$ if minimum wage method was considered and a minimum of $10.4 \%$ (1.4-41.8 \%) when income per capita for the socio-economic class was considered. These proportions of the income attaining over $40 \%$ for 56 (44\%) patients and 34 (27\%) respectively (Additional file 1: Table S7 in supplementary material).

\section{Discussion}

We present a comprehensive cost study describing detailed information on first-line regimen costs that can serve as an input for decision-making and budget preparation for NTPs when considering the introduction of new shortened regimens. We estimated the methods of delivery to be the main driver of overall costs. From a health service perspective, community-DOT was the main contributor to total costs for first-line TB treatment in these primary care facilities, mainly due to high service utilisation (domiciliary visits by community health care agents). SAT was estimated to be the treatment modality with the highest unit cost, even though it was the treatment model contributing the least to total costs, due to the least number of visits. From a patient perspective, facility-based services (both SAT and facility-DOT) were modalities representing the highest costs for the patients, mainly associated to transport and 
Table 3 Total, direct and indirect costs incurred by patients during the last two months of treatment in Rio de Janeiro, Brazil (using four methods for productivity loss valuation ${ }^{\mathrm{a}}$ ), USD 2013

\begin{tabular}{|c|c|c|c|c|}
\hline Costs & $\begin{array}{l}\text { Minimum wage, } \\
\text { mean (SD) } N=126\end{array}$ & $\begin{array}{l}\text { SES income per capita, } \\
\text { mean (SD) } N=126\end{array}$ & $\begin{array}{l}\text { Income per activity, } \\
\text { mean (SD) } N=126\end{array}$ & $\begin{array}{l}\text { Reported income, } \\
\text { mean (SD) } N=49\end{array}$ \\
\hline Total direct costs (all) ${ }^{\mathrm{b}}$ & 96 (148) & & & $114(162)$ \\
\hline Transport & $8(19)$ & & & $5(11)$ \\
\hline Food & $2(5)$ & & & $2(5)$ \\
\hline Other non-transport/food & $3(21)$ & & & $0.5(3)$ \\
\hline Nutritional supplements & $82(143)$ & & & $105(158)$ \\
\hline Total indirect costs (all) ${ }^{\mathrm{b}}$ & $316(1,466)$ & $316(1,469)$ & $332(1,472)$ & $357(1,985)$ \\
\hline Coping costs ${ }^{d}$ & $275(1,458)$ & & & $327(1,982)$ \\
\hline Productivity loss & $21(24)$ & $18(26)$ & $30(32)$ & $25(39)$ \\
\hline Caregiver/guardian costs & $20(67)$ & $22(78)$ & $27(94)$ & $5(23)$ \\
\hline Total costs $(\mathrm{all})^{\mathrm{b}}$ & $413(1,503)$ & $413(1,507)$ & $153(206)$ & $144(163)$ \\
\hline Total costs (patients only) ${ }^{c}$ & $361(1,481)$ & $364(1,484)$ & $374(1,486)$ & $411(1,991)$ \\
\hline Total direct costs & $51(74)$ & & & $57(77)$ \\
\hline Total indirect costs & $310(1,466)$ & $313(1,469)$ & $323(1,471)$ & $354(1,981)$ \\
\hline
\end{tabular}

${ }^{a}$ Minimum wage refers to the valuation of an productive hour lost based on the minimum wage in Brazil and a 44 weekly hour contract; SES income per capita refers to the valuation of a productive hour based on the average income for a reported socio-economic status; Income activity refers to the valuation of a productive hour based on the average income for the patient's profession, based on union's information; Reported income refers to the valuation of a productive hour based on the income reported by the participant. ${ }^{\mathrm{b}}$ These costs are presented for both patients and any person accompanying the patient during their visits. ${ }^{\mathrm{c}}$ These costs refer to costs incurred by patients only, not including costs incurred by any accompanying person. ${ }^{\mathrm{d} C o p i n g}$ costs include borrowed money and selling of assets

productivity loss costs. Therefore, while bringing services to the community might seem more costly from a health service perspective, it can lead to substantial savings from a societal perspective. Besides costs, decisionmakers should take into account the potential improvement brought by community-based treatment regarding treatment outcomes and equity in the access to care for an already vulnerable population. While the patient-level benefits of community-DOT compared to facility-DOT have been suggested in three clinical trials, the benefits of DOT over SAT are still controversial [32, 33]. Additionally, although general access to care and healthcare utilization has improved with the Family Health Program expansion in Brazil [34], TB treatment outcomes have not [35].

In terms of cost differences among models of service delivery, our results are consistent with two previous studies in the country $[7,36]$. However, Steffen et al. estimates were based on staff costs exclusively and the authors assumed that service utilisation at the facility-level was the same for SAT or DOT, but much lower for pill collection visits, explaining the lower cost estimates for the pill collecting visits at USD 7.5 (USD 9.4 in 2012) [7]. In addition, at the time of study (2008), community-DOT was the exception in Rio de Janeiro. Although they found SAT to be more cost-effective than DOT, community-DOT was not evaluated. In our study, community-DOT was the strategy with the lowest unit costs, both from the health service and patient perspectives.
We found a large variation both across clinics and between the top-down and bottom-up approaches, mainly due to estimations of staff time. While a top-down method might be less precise when disaggregating costs per activity, especially for staff costs allocation, it might be a more accurate representation of total costs, including inefficiencies in service delivery. Compared to the USD 88,000,000 national budget for TB control, the potential estimated savings should a four-month regimen be introduced nationally could represent up to 9-18\% of the NTP budget. These savings could be realised in their totality if, for example, staff would be relocated to other programmes. As this might not be the case, we are offering a top end estimate of potential savings. On the other hand, our estimates of potential cost benefits are likely to be conservative because potential savings due to a possible reduction in transmission and the possible differential in health improvements, with less side effects and therefore service utilisation during the last months of treatment, were not considered.

Costs of treatment for patients can be a significant barrier to access and utilisation of healthcare [18, 37-39], even in health systems where drugs and services are free-of-charge, as is the case in Brazil. In the present study, during the two last months of treatment, when patients have usually recovered from symptoms present at diagnosis and are often fit to work, the costs incurred by patients still represent a substantial proportion of their income. We estimated that the introduction of shortened regimens may prevent 
Table 4 Factors associated with costs incurred by patients during the last two months of treatment in Rio de Janeiro, using income per activity reported by participant to value a productive hour (USD 2013)

\begin{tabular}{|c|c|c|c|c|c|c|c|}
\hline Variables & $\begin{array}{l}\text { Number in each category } \\
\text { with direct costs }\end{array}$ & $\begin{array}{l}\text { Direct costs, mean } \\
\text { (SD) } N=85^{b}\end{array}$ & $\begin{array}{l}P \\
\text { value }^{\mathrm{a}}\end{array}$ & $\begin{array}{l}\text { Indirect costs, mean } \\
\text { (SD) } N=126\end{array}$ & $\begin{array}{l}P \\
\text { value }^{a}\end{array}$ & $\begin{array}{l}\text { Total costs, mean } \\
\text { (SD) } N=126\end{array}$ & $\begin{array}{l}P- \\
\text { value }^{a}\end{array}$ \\
\hline \multicolumn{8}{|l|}{$\overline{S e x^{b}}$} \\
\hline Female & 32 & 79 (126) & 0.313 & $355(1,981)$ & 0.892 & $127(145)$ & 0.263 \\
\hline Male & 53 & $107(161)$ & & $318(1,040)$ & & $169(236)$ & \\
\hline \multicolumn{8}{|l|}{ Age } \\
\hline$<43$ years & 41 & $105(165)$ & 0.527 & 289 (998) & 0.743 & $167(251)$ & 0.451 \\
\hline$>=43$ years & 44 & $88(131)$ & & 375 (1834) & & 139 (139) & \\
\hline \multicolumn{8}{|l|}{ Treatment history } \\
\hline New case & 71 & $101(155)$ & 0.544 & $373(1,628)$ & 0.524 & $153(217)$ & 0.952 \\
\hline Retreatment & 14 & $80(116)$ & & 159 (299) & & $150(157)$ & \\
\hline \multicolumn{8}{|l|}{ Residence } \\
\hline Urban & 56 & $88(152)$ & 0.351 & 258 (978) & 0.386 & $135(213)$ & 0.166 \\
\hline Peri-urban & 29 & $114(140)$ & & $500(2,193)$ & & $190(187)$ & \\
\hline \multicolumn{8}{|l|}{ Treatment type } \\
\hline SAT & 52 & $110(165)$ & 0.379 & $560(49)$ & 0.216 & $170(256)$ & 0.333 \\
\hline Facility-DOT & 29 & $93(137)$ & & $126(185)$ & & $154(142)$ & \\
\hline Community-DOT & 4 & $52(104)$ & & $39(49)$ & & $81(122)$ & \\
\hline \multicolumn{8}{|l|}{ Socioeconomic status ${ }^{c}$} \\
\hline $\begin{array}{l}\text { A/B (median family income } \\
\text { USD 4288.4-USD 1228.7) }\end{array}$ & 18 & $60(108)$ & 0.128 & $68(137)$ & 0.042 & $98(121)$ & 0.099 \\
\hline $\begin{array}{l}\text { C/D/E (median family income } \\
\text { USD 780.1-USD 359.2) }\end{array}$ & 64 & $111(160)$ & & $428(1,703)$ & & $175(227)$ & \\
\hline
\end{tabular}

Abbreviations: SAT self-administered therapy; DOT directly observed therapy; SD standard deviation

"from independent $t$-test

${ }^{\mathrm{b}}$ Among 126 patients, 85 patients or accompanying persons declared direct costs

cmissing information for 3 participants

Bold numbers highlight significant $p$-values.

catastrophic expenditure for 27 to $44 \%$ of individuals in our sample, depending on the method used to estimate the value of a productive hour. This result is comparable to previous results in Tanzania and Bangladesh, where the total patients costs of six months of treatment represented 103 and $117 \%$ of the per capita income, respectively [18].

In our study, costs for patients were significantly higher for those in the lower socioeconomic classes. Because their productive hour is less valued, we would expect lower indirect costs. Our finding (higher indirect costs) suggests that, no matter which method is used to estimate them, more hours are spent in or traveling to the facilities and raises more concern about the added vulnerability to an already disadvantaged population. The introduction of a shortened regimen would then benefit lower socio-economic class patients the most.

Our study presents several limitations. We collected data in one only city, including both urban and periurban but excluding rural settings. Therefore, the findings can only be generalised to similar settings within Brazil. Additionally, we present potential cost savings during the last 2 months of treatment only and patients incur substantial costs during the pre-diagnosis period [40-42]. In our analysis, we assumed that these costs (pre-diagnosis) would not change, should a shortened regimen be introduced. Additionally, while we aimed to report income loss, this measure might not represent societal productivity loss (due to replacement). An additional limitation is the use of routine data to measure service utilisation. Program indicators reported patients by treatment delivery model but not by treatment phase. The assumptions made about the distribution between patients in the intensive as opposed to continuation phase may have led to an over-estimation of unit costs. Conversely, the study presents significant strengths. Detailed cost data were collected from a societal perspective, from patients and clinics in diverse neighbourhoods adopting different models of treatment. Finally, when faced with uncertainty in assumptions such as the value of a productive hour and the distribution of patients between intensive and continuation phase, we present several estimation methods to test the robustness of our conclusions to these assumptions. 


\section{Conclusion}

Altogether, our findings show that significant savings can be achieved for patients and the health system with the introduction of shortened regimens. This is an important finding that sustains the rationale for shorter regimens even with equivalent effectiveness to the currently recommended 6-month regimen. We also highlighted the importance of considering the variation among models of delivery when undertaking cost-effectiveness analyses of future drugs. As the numbers of confirmed TB patients may increase with the introduction of new diagnostics [14], potentially reducing the number of patients empirically treated, it will be important to continue investing on TB programs, not only due to the potential health impact on patients outcomes but also to achieve potential cost gains, helping to avoid catastrophic costs for patients and to attain the post-2015 targets.

\section{Additional file}

Additional file 1: Supplement material. (DOCX 69 kb)

\begin{abstract}
Abbreviations
BRL: Brazilian real; DOT: directly observed treatment; IQR: interquartile range; NTP: National Tuberculosis Programme; SAT: self-administered treatment; TB: tuberculosis; USD: United States dollar; WHO: World Health Organization.
\end{abstract}

\section{Competing interests}

The authors declare that they have no competing interests.

\section{Authors' contributions}

AV, GBG, WAW and FC conceived the study. MLB, AT, MB, JC, JG, AMS and CMS interviewed patients. MLB, MB, AT and RTB collected health facility data. MLB, GBG and AT analysed the data. AT and GBG drafted the first version of the manuscript. All authors read and approved the final manuscript.

\section{Authors' information}

WAW was not at United States Agency for International Development (USAID) when the research for the current paper was conducted. The views and opinions expressed in this paper are those of the authors and not necessarily the views and opinions of the USAID.

\section{Acknowledgements}

The authors are very grateful to all the patients and healthcare professionals in Rio de Janeiro for their time and dedication.

\section{Funding statement}

This study was conducted as part of a multi-country project funded by The Global Alliance for TB Drug Development (VALUE-TB) in Bangladesh, Brazil, South Africa, and Tanzania.

\footnotetext{
Author details

${ }^{1}$ Federal University of Rio de Janeiro, Rio de Janeiro, Brazil. ${ }^{2}$ McGill University, Montreal, Canada. ${ }^{3}$ Tuberculosis Scientific League, Rio de Janeiro, Brazil. ${ }^{4}$ Souza Marques Foundation, Rio de Janeiro, Brazil. ${ }^{5}$ Rio de Janeiro Municipal Health Department, Rio de Janeiro, Brazil. ${ }^{6} \mathrm{Global}$ Alliance for TB Drug Development, New York, USA. ${ }^{7}$ Current address: United States Agency for International Development, Washington, DC, USA. ${ }^{8}$ Amsterdam Institute for Global Health and Development and Department of Global Health, Academic Medical Center, University of Amsterdam, Amsterdam, The Netherlands. ${ }^{9}$ Department of Global Health and Development, London School of Hygiene and Tropical Medicine, London, UK.
}

Received: 19 June 2015 Accepted: 12 January 2016

Published online: 22 January 2016

\section{References}

1. World Health Organization. Global Tuberculosis Report 2014. Geneva, Switzerland: $\mathrm{WHO}$; 2014. p. 171

2. Migliori GB, Matteelli A, Cirillo D, Pai M. Diagnosis of multidrug-resistant tuberculosis and extensively drug-resistant tuberculosis: Current standards and challenges. Can J Infect Dis Med Microbiol J Can Mal Infect Microbiol Médicale AMMI Can. 2008;19:169-72.

3. World Health Organization. WHO | Towards Universal Access to Diagnosis and Treatment of Multidrug-Resistant and Extensively Drug-Resistant Tuberculosis by 2015. Geneva, Switzerland: WHO; 2011. p. 119.

4. World Health Organization. Fluorescent light-emitting diode (LED) microscopy for diagnosis of tuberculosis. Geneva: World Health Organization; 2011.

5. Ling DI, Zwerling AA, Pai M. GenoType MTBDR assays for the diagnosis of multidrug-resistant tuberculosis: a meta-analysis. Eur Respir J Off J Eur Soc Clin Respir Physiol. 2008;32:1165-74.

6. Steingart KR, Sohn H, Schiller I, Kloda LA, Boehme CC, Pai M, et al. Xpert ${ }^{\oplus}$ MTB/ RIF assay for pulmonary tuberculosis and rifampicin resistance in adults. In: The Cochrane Collaboration, Steingart KR, editors. Cochrane Database of Systematic Reviews. Chichester, UK: John Wiley \& Sons, Ltd; 2013.

7. Steffen $R$, Menzies D, Oxlade O, Pinto M, de Castro AZ, Monteiro $P$, et al. Patients' costs and cost-effectiveness of tuberculosis treatment in DOTS and non-DOTS facilities in Rio de Janeiro, Brazil. PloS One. 2010;5:e14014.

8. Barter DM, Agboola SO, Murray MB, Bärnighausen T. Tuberculosis and poverty: the contribution of patient costs in sub-Saharan Africa-a systematic review. BMC Public Health. 2012;12:980.

9. Tanimura T, Jaramillo E, Weil D, Raviglione M, Lönnroth K. Financial burden for tuberculosis patients in low- and middle-income countries: a systematic review. Eur Respir J. 2014;43:1763-75.

10. Gillespie SH, Crook AM, McHugh TD, Mendel CM, Meredith SK, Murray SR, et al. Four-Month Moxifloxacin-Based Regimens for Drug-Sensitive Tuberculosis. N Engl J Med. 2014;371:1577-87.

11. Merle CS, Fielding K, Sow OB, Gninafon M, Lo MB, Mthiyane T, et al. A FourMonth Gatifloxacin-Containing Regimen for Treating Tuberculosis. N Engl J Med. 2014;371:1588-98.

12. Jindani A, Harrison TS, Nunn AJ, Phillips PPJ, Churchyard GJ, Charalambous S, et al. High-Dose Rifapentine with Moxifloxacin for Pulmonary Tuberculosis. N Engl J Med. 2014:371:1599-608.

13. Ginsberg A. The TB Alliance: overcoming challenges to chart the future course of TB drug development. Future Med Chem. 2011;3:1247-52.

14. Durovni B, Saraceni V, van den Hof S, Trajman A, Cordeiro-Santos M, Cavalcante $\mathrm{S}$, et al. Impact of replacing smear microscopy with Xpert MTB/ RIF for diagnosing tuberculosis in Brazil: a stepped-wedge clusterrandomized trial. PLoS Med. 2014;11:e1001766.

15. Durovni B, Saraceni V, Cordeiro-Santos M, Cavalcante S, Soares E, Lourenço C, et al. Operational lessons drawn from pilot implementation of Xpert MTB/Rif in Brazil. Bull World Health Organ. 2014;92:613-7.

16. Owens JP, Fofana MO, Dowdy DW. Cost-effectiveness of novel first-line treatment regimens for tuberculosis. Int J Tuberc Lung Dis. 2013;17:590-6.

17. World Health Organization. Global Strategy and Targets for Tuberculosis Prevention, Care and Control after 2015. Geneva: WHO; 2014.

18. Gospodarevskaya E, Tulloch O, Bunga C, Ferdous S, Jonas A, Islam S, et al. Patient costs during tuberculosis treatment in Bangladesh and Tanzania: the potential of shorter regimens. Int J Tuberc Lung Dis Off J Int Union Tuberc Lung Dis. 2014;18:810-7.

19. FIND. FIND Participates in Largest Ever Gathering of Stop TB Partners in Rio. Conference report; March 09.

20. de Souza FBA, Villa TCS, Cavalcante SC, Ruffino Netto A, Lopes LB, Conde MB. Peculiarities of tuberculosis control in a scenario of urban violence in a disadvantaged community in Rio de Janeiro, Brazil. J Bras Pneumol. 2007:33:318-22.

21. PNAB- Política Nacional de Atenção Básica. Brasília. Brasil: Ministério da Saúde. Secretaria de Atenção à Saúde. Departamento de Atenção Básica; 2012.

22. Ministério da Saúde. Programa Nacional de Controle da Tuberculose: Manual de Recomendações Para O Controle Da Tuberculose No Brasil. 
23. Conteh L, Walker D. Cost and unit cost calculations using step-down accounting. Health Policy Plan. 2004;19:127-35.

24. Fox-Rushby JA, Cairns J, editors. Economic Evaluation. Maidenhead; New York: Open University Press; 2005 [Understanding Public Health].

25. World Health Organization, UNICEF, Aga Khan Foundation. Cost Analysis in Primary Health Care: A Training Manual for Programme Managers. Geneva: World Health Organization; 1994.

26. GDF Product Catalogue [http://www.stoptb.org/gdf/drugsupply/drugs_ available.asp]

27. The Tool to Estimate Patients' Costs [http://www.stoptb.org/wg/dots_ expansion/tbandpoverty/assets/documents/ Tool\%20to\%20estimate\%20Patients'\%20Costs.pdf]

28. Associação Brasileira de Empresas de Pesquisa: Critério de Classificação Econômica Brasil. 2013.

29. Lei do Estado do Rio de Janeiro N 6702 DE 11032014. Institui Pisos Salariais no Âmbito do estado do Rio de Janeiro. [http://www.normaslegais.com.br/ legislacao/lei-ri-6702-2014.htm]

30. Decreto-Lei N. ${ }^{\circ}$ 5.452. Aprova a Consolidação Das Leis Do Trabalho de 10 de Maio de 1943. 1943.

31. Xu K, Evans DB, Kawabata K, Zeramdini R, Klavus J, Murray CJL. Household catastrophic health expenditure: a multicountry analysis. Lancet. 2003;362:111-7.

32. Volmink J, Garner P. Directly observed therapy for treating tuberculosis. Cochrane Database Syst Rev. 2007:4:CD003343.

33. Suwankeeree W, Picheansathian W. Strategies to promote adherence to treatment by pulmonary tuberculosis patients: a systematic review. Int $」$ Evid Based Healthc. 2014;12:3-16.

34. Crispim J d A, Scatolin BE, Da Silva LMC, Pinto IC, Palha PF, Arcêncio RA. Agente Comunitário de Saúde no controle da tuberculose na Atenção Primária à Saúde. Acta Paul Enferm. 2012;25:721-7.

35. Ignotti E, Oliveira BFA D, Hartwig S, Oliveira HC D, Scatena JHG. Analysis of the Tuberculosis Control Program in the city of Cáceres, Brazil, prior to and after the implementation of a Family Health Program. J Bras Pneumol Publicaçäo Of Soc Bras Pneumol E Tisilogia. 2007;33:287-94.

36. Costa JG, Santos AC, Rodrigues LC, Barreto ML, Roberts JA. [Tuberculosis in Salvador, Brazil: costs to health system and families]. Rev Saúde Pública. 2005:39:122-8.

37. Long Q, Smith H, Zhang T, Tang S, Garner P. Patient medical costs for tuberculosis treatment and impact on adherence in China: a systematic review. BMC Public Health. 2011;11:393.

38. Mauch V, Woods N, Kirubi B, Kipruto H, Sitienei J, Klinkenberg E. Assessing access barriers to tuberculosis care with the tool to Estimate Patients' Costs: pilot results from two districts in Kenya. BMC Public Health. 2011;11:43.

39. Ukwaja KN, Alobu I, Lgwenyi C, Hopewell PC. The high cost of free tuberculosis services: patient and household costs associated with tuberculosis care in Ebonyi State, Nigeria. PloS One. 2013;8:e73134.

40. Aspler A, Menzies D, Oxlade O, Banda J, Mwenge L, Godfrey-Faussett P, et al. Cost of tuberculosis diagnosis and treatment from the patient perspective in Lusaka, Zambia. Int I Tuberc Lung Dis Off J Int Union Tuberc Lung Dis. 2008;12:928-35.

41. da Silva AR, Pinto M, Trajman A. Patient costs for the diagnosis of tuberculosis in Brazil: comparison of Xpert MTB/RIF and smear microscopy. Int J Tuberc Lung Dis Off J Int Union Tuberc Lung Dis. 2014;18:547-51.

42. Mauch V, Bonsu F, Gyapong M, Awini E, Suarez P, Marcelino B, et al. Free tuberculosis diagnosis and treatment are not enough: patient cost evidence from three continents. Int J Tuberc Lung Dis Off J Int Union Tuberc Lung Dis. 2013;17:381-7.

43. Cadastro Nacional de Estabelecimentos de Saúde - CNES [http://cnes. datasus.gov.br/]

44. Bairros Cariocas - Armazém de Dados [http://portalgeo.rio.rj.gov.br/ bairroscariocas/]

45. Análise de Situações de Saúde - Dados Vitais - rio.rj.gov.br [http://www.rio. rj.gov.br/web/sms/analise-situacoes-saude]

\section{Submit your next manuscript to BioMed Central and we will help you at every step:}

- We accept pre-submission inquiries

- Our selector tool helps you to find the most relevant journal

- We provide round the clock customer support

- Convenient online submission

- Thorough peer review

- Inclusion in PubMed and all major indexing services

- Maximum visibility for your research

Submit your manuscript at www.biomedcentral.com/submit
Biomed Central 